\title{
Searching for phylogenetic patterns of Symbiodiniaceae community structure among Indo-Pacific Merulinidae corals
}

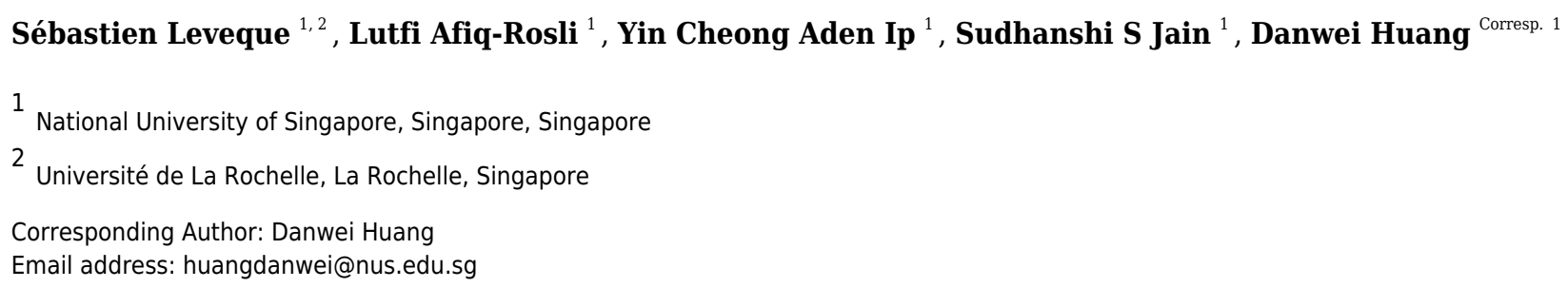

Over half of all extant stony corals (Cnidaria: Anthozoa: Scleractinia) harbour endosymbiotic dinoflagellates of the family Symbiodiniaceae, forming the foundational species of modern shallow reefs. However, whether these associations are conserved on the coral phylogeny remains unknown. Here we aim to characterise Symbiodiniaceae communities in eight closely-related species in the genera Merulina, Goniastrea and Scapophyllia, and determine if the variation in endosymbiont community structure can be explained by the phylogenetic relatedness among hosts. We perform DNA metabarcoding of the nuclear internal transcribed spacer 2 using Symbiodiniaceae-specific primers on 30 coral colonies to recover three major endosymbiont clades represented by 23 distinct types. In agreement with previous studies on Southeast Asian corals, we find an abundance of Cladocopium and Durusdinium, but also detect Symbiodinium types in three of the eight coral host species. Interestingly, differences in endosymbiont community structure are dominated by host variation at the intraspecific level, rather than interspecific, intergeneric or among-clade levels, indicating a lack of phylogenetic constraint in the coral-endosymbiont association among host species. Furthermore, the limited geographic sampling of four localities spanning the Western and Central IndoPacific preliminarily hints at large-scale spatial structuring of Symbiodiniaceae communities. More extensive collections of corals from various regions and environments will help us better understand the specificity of the coral-endosymbiont relationship. 


\section{Searching for phylogenetic patterns of}

\section{Symbiodiniaceae community structure among Indo-}

3 Pacific Merulinidae corals

4

5 Sébastien Leveque ${ }^{1,2}$, Lutfi Afiq-Rosli ${ }^{1,3}$, Yin Cheong Aden Ip ${ }^{1}$, Sudhanshi S. Jain ${ }^{1}$, Danwei

6 Huang ${ }^{1,3 *}$

7

$8{ }^{1}$ Department of Biological Sciences, National University of Singapore, Singapore 117558,

9 Singapore

$10 \quad{ }^{2}$ Faculté des Sciences et Technologies, Université de La Rochelle, La Rochelle 17042, France

$11{ }^{3}$ Tropical Marine Science Institute, National University of Singapore, Singapore 119227,

12 Singapore

13

14 Corresponding Author:

15 Danwei Huang*

16 Department of Biological Sciences, National University of Singapore, 16 Science Drive 4,

17 Singapore 117558, Singapore

18 Email address: huangdanwei@nus.edu.sg 


\section{Abstract}

21 Over half of all extant stony corals (Cnidaria: Anthozoa: Scleractinia) harbour endosymbiotic

22

23

24

25

26

27

28

29

30

31

32

33

34

35

36

37

38

39

40

41

42

43

44

45

46

47

48

49

50

51

52

53

54

55

56

57

58

59

dinoflagellates of the family Symbiodiniaceae, forming the foundational species of modern shallow reefs. However, whether these associations are conserved on the coral phylogeny remains unknown. Here we aim to characterise Symbiodiniaceae communities in eight closelyrelated species in the genera Merulina, Goniastrea and Scapophyllia, and determine if the variation in endosymbiont community structure can be explained by the phylogenetic relatedness among hosts. We perform DNA metabarcoding of the nuclear internal transcribed spacer 2 using Symbiodiniaceae-specific primers on 30 coral colonies to recover three major endosymbiont clades represented by 23 distinct types. In agreement with previous studies on Southeast Asian corals, we find an abundance of Cladocopium and Durusdinium, but also detect Symbiodinium types in three of the eight coral host species. Interestingly, differences in endosymbiont community structure are dominated by host variation at the intraspecific level, rather than interspecific, intergeneric or among-clade levels, indicating a lack of phylogenetic constraint in the coral-endosymbiont association among host species. Furthermore, the limited geographic sampling of four localities spanning the Western and Central Indo-Pacific preliminarily hints at large-scale spatial structuring of Symbiodiniaceae communities. More extensive collections of corals from various regions and environments will help us better understand the specificity of the coral-endosymbiont relationship.

\section{Introduction}

The modern coral reef is one of the most diverse marine ecosystems on Earth (Reaka-Kudla, 1997; Fisher et al., 2015), build mainly by the habitat-forming stony corals (Cnidaria: Anthozoa:

Scleractinia) with a calcification process driven largely by their intricate symbiosis with photosynthetic dinoflagellates of the family Symbiodiniaceae (Muscatine \& Cernichiari, 1969;

Stat et al., 2006). The host provides shelter and inorganic nutrients to the endosymbionts (Muscatine \& Porter, 1977; Weis et al., 2001; Stat et al., 2006) in exchange for fixed carbon (Muscatine \& Cernichiari, 1969; Weis et al., 2001; Yellowlees et al., 2008).

Symbiodiniaceae is extremely diverse, with at least nine genus-level clades which contain hundreds of species (Arif et al., 2014; Thornhill et al., 2014), although fewer than 30 species have been formally named (LaJeunesse et al., 2018). The recognition of this remarkable diversity owes in large part to the use of molecular genetic tools that have helped biologists discover and characterise the major clades and subclades (or types) of Symbiodiniaceae (Rowan \& Powers, 1991a, b; Rowan, 1998; LaJeunesse, 2002). For decades, these clades have been referred to by letters that run from A to I, but genus names have recently been established for most of them, including Symbiodinium Gert Hansen \& Daugbjerg, 2009 (formerly Clade A), Breviolum J.E.Parkinson \& LaJeunesse, 2018 (formerly Clade B), Cladocopium LaJeunesse \& H.J.Jeong, 2018 (formerly Clade C), and Durusdinium LaJeunesse, 2018 (formerly Clade D) (LaJeunesse et al., 2018). A robust phylogenetic classification of these dinoflagellates is critical for better understanding the coral reef ecosystem because different endosymbiont types have

Peer) reviewing PDF | (2019:04:36661:1:0:NEW 1 Aug 2019) 
60

61

62

63

64

65

66

67

68

69

70

71

72

73

74

75

76

77

78

79

80

81

82

83

84

85

86

87

88

89

90

91

92

93

94

95

96

97

98

99

distinct physiological characteristics (Warner et al., 1996; Baker, 2003; Sampayo et al., 2008) that result in broadly predictable responses of reef corals to environmental stress (Warner et al., 1999; Baker et al., 2004; Reynolds et al., 2008). For example, coral hosts dominated by Durusdinium can generally better withstand thermal stress compared to corals with a greater abundance of Cladocopium (Rowan, 2004; Berkelmans \& van Oppen, 2006; LaJeunesse et al., 2014).

Reef corals exhibit varying levels of specificity for particular genera and types of endosymbionts (Thomas et al., 2014; Smith et al., 2017a). Generally, host species in the IndoPacific are mostly associated with the genus Cladocopium and to a lesser extent Durusdinium (LaJeunesse et al., 2010a), though endosymbioses with Symbiodinium and Breviolum have also been documented (Loh et al., 1998; Yang et al., 2012). Each host colony can also associate with multiple Symbiodiniaceae types (Rowan \& Powers, 1991b; Rowan \& Knowlton, 1995; Baker, 2003). For example, a single colony of Porites lutea can harbour three species of CladocopiumC3, C15 and C91 (Gong et al., 2018). Environmental factors may also play a role in the distribution of Symbiodiniaceae among different colonies of a single host species. For instance, the relative abundances of Cladocopium goreaui (C1), Cladocopium C2, and Durusdinium glynni (D1) in Acropora millepora are dependent on temperature and light availability (Cooper et al., 2011). Dissolved nutrients have also been shown to influence the community structure of the endosymbionts present within the host (Sawall et al., 2014; Gong et al., 2018).

Apart from the coral host's ability to harbour a wide range of Symbiodiniaceae species, the composition of endosymbionts present in a host population can change in response to environmental variations. For example, following a bleaching event, Acropora millepora colonies that were originally dominated by the thermally sensitive Cladocopium C3 (=ITS1 type C2; Tonk et al., 2013) suffered higher mortality compared with colonies that were Durusdinium predominant (Jones et al., 2008). Furthermore, the majority of the surviving colonies that were initially Cladocopium C3-predominant acquired more Cladocopium goreaui or Durusdinium endosymbionts (Jones et al., 2008). Indeed, the ability to shuffle and even switch symbiont communities by repopulation of more tolerant types can play an important role towards enhancing the holobiont's recovery capacity and host survivability (LaJeunesse et al., 2010b; Kemp et al., 2014; Silverstein et al., 2015). Overall, however, the host-symbiont association in the majority of corals tends to be stable, even in the course of severe bleaching events (Goulet, 2006; Smith et al., 2017b). This stability may play a crucial role in the hosts' resilience during acute environmental stress.

Recently, host identities of populations and species of Pocilloporidae Gray, 1840, have been shown to affect associated Symbiodiniaceae and bacterial communities (Bongaerts et al., 2010, 2011; Brener-Raffalli et al., 2018). Whether this phylogenetic constraint extends beyond intraspecific relationships or sister species is unclear. With rapid advances in our understanding of coral evolutionary history and taxonomy in the past decade (Frank \& Mokady, 2002; Budd et al., 2010), we now can now bear on this question using an abundance of phylogenetic data (Bhattacharya et al., 2016; Kitahara et al., 2016; Quek \& Huang, 2019). It is generally 
100

101

102

103

104

105

106

107

108

109

110

111

112

113

114

115

116

117

118

119

120

121

122

123

124

125

126

127

128

129

130

131

132

133

134

135

136

137

138

acknowledged that gross morphological traits can converge among distinct taxa living under similar environmental influences and these traits evolve at vastly different rates among lineages (Cairns, 2001; Fukami et al., 2004b; Flot et al., 2011), partly explaining why taxonomy based solely on morphology has been problematic (Fukami, 2008; Fukami et al., 2008; Kitahara et al., 2010). However, there exist a number of species traits which are phylogenetically constrained among corals, in that closely-related species tend to possess similar trait states (Madin et al., 2016a). These include growth rates (Madin et al., 2016b), sexuality (Baird et al., 2009), reproductive mode (Kerr et al., 2011), endosymbiont transmission strategy (Hartmann et al., 2017), and even susceptibility to and resistance against anthropogenic stressors (Huang, 2012; Huang \& Roy, 2013). The present study extends this line of inquiry to determine if endosymbiont communities are constrained by the phylogenetic relationships among hosts, focusing on a clade of three genera in the family Merulinidae Verrill, 1865, that have a wellcharacterised phylogeny (Huang et al., 2014a). These corals obtain their algal symbionts from the environment (horizontal acquisition), in contrast to the well-studied pocilloporids which vertically transmit their endosymbionts, and thus offer a distinct life history strategy for study (Baird et al., 2009; Hartmann et al., 2017).

Merulinidae is a clade containing 25 living genera with around 140 species distributed widely in the Indo-Pacific and Caribbean Sea (Veron, 2000; Huang et al., 2014a, b). Since the landmark studies of Fukami et al. $(2004 b$, 2008) that showed severe polyphyly involving four traditional families of Merulinidae Verrill, 1865, Faviidae Gregory, 1900, Pectiniidae Vaughan \& Wells, 1943, and Trachyphylliidae Verrill, 1901, there has been considerable progress in building a phylogenetic classification of the clade (Huang et al., 2009, 2011, 2014b; Budd \& Stolarski, 2011; Benzoni et al., 2011; Arrigoni et al., 2012; Budd et al., 2012). In particular, one subclade ('A' sensu Budd \& Stolarski, 2011) comprising the genera Merulina Ehrenberg, 1834, Goniastrea Milne Edwards \& Haime, 1848, Scapophyllia Milne Edwards \& Haime, 1848, and Paraclavarina Veron, 1985, was analysed in detail using both nuclear and mitochondrial DNA markers to produce a well-supported phylogeny (Fig. 1). The groups defined by these supports (e.g. A1 and A3 sensu Huang et al., 2014a) could be tested for phylogenetic conservatism of Symbiodiniaceae communities hosted by these corals.

Here, we apply DNA metabarcoding using the internal transcribed spacer 2 (ITS2) marker to test if closer lineages of merulinid corals host more similar communities and diversity of Symbiodiniaceae types (Quigley et al., 2014). We also test if the endosymbiont communities are structured according to conventional host taxonomy or geographic locality. The data show that endosymbiont community variation within host species overwhelms interspecific, intergeneric and among-lineage differences, and geography may play a role in structuring Symbiodiniaceae communities among closely-related corals.

\section{Materials \& Methods}

\section{Field sampling}


139 Samples from eight merulinid species - Goniastrea retiformis (Lamarck, 1816), G. pectinata

140 (Ehrenberg, 1834), G. favulus (Dana, 1846), G. edwardsi Chevalier, 1971, G. minuta Veron, 141 2000, Merulina ampliata (Ellis \& Solander, 1786), M. scabricula Dana, 1846, and Scapophyllia

142 cylindrica Milne Edwards \& Haime, 1849-were collected from Singapore, Fiji, Seychelles and 143 the Great Barrier Reef in Australia (Table S1). Field collections were approved by the National 144 Parks Board Singapore (NP/RP16-156), Fiji Ministry of Education (21/10/10), Seychelles 145 Bureau of Standards (A0347), and Great Barrier Reef Marine Park Authority (G09/29715.1). In 146 total, 30 healthy colonies were sampled across localities, with sampling at each locality 147 performed within a maximum of one week, except for Singapore, for which samples were 148 obtained in two batches in 2007 and 2017. Sampling periods were tracked to check if 149 Symbiodiniaceae communities differed between them. Coral colonies were photographed in the

150

151

152

153

154

155

156

157

158

159

160

161

162

163

164

165

166

167

168

169

170

171

172

173

174

175

176

177

178 field and a 10 to $100 \mathrm{~cm}^{2}$ piece of tissue was sampled and preserved in $100 \%$ ethanol or CHAOS solution (4 M guanidine thiocyanate, $0.1 \% \mathrm{~N}$-lauroyl sarcosine sodium, $10 \mathrm{mM}$ Tris $\mathrm{pH} 8,0.1 \mathrm{M}$ 2-mercaptoethanol) (Sargent et al., 1986; Fukami et al., 2004a; Huang et al., 2008).

\section{DNA extraction, amplification and sequencing}

Isolation of digested material from CHAOS-preserved samples was performed with a phenol extraction buffer (100 mM TrisCl pH 8, $10 \mathrm{mM}$ EDTA, 0.1\% SDS), while ethanol-preserved samples were digested overnight with $900 \mu \mathrm{CTAB}$ buffer (cetyltrimethylammonium bromide; $0.1 \mathrm{M}$ Tris $\mathrm{pH} 8,1.4 \mathrm{M} \mathrm{NaCl}, 0.02 \mathrm{M}$ EDTA, $20 \mathrm{~g} / \mathrm{l} \mathrm{CTAB})$ and $20 \mu$ proteinase $\mathrm{K}(20 \mathrm{mg} / \mathrm{ml})$. Phase separation was carried out using phenol:chloroform:isoamyl-alcohol (25:24:1), and precipitated DNA was eluted in $100-200 \mu$ of water and stored at $-80^{\circ} \mathrm{C}$.

Polymerase chain reaction (PCR) amplified a $\sim 350$-bp fragment from the nuclear ribosomal internal transcribed spacer 2 (ITS2) region, targeted using a Symbiodiniaceae-specific primer set: ITSintfor2 (forward: 5'-GAA TTG CAG AAC TCC GTG-3'; LaJeunesse \& Trench, 2000) and ITS-Reverse (reverse: 5'-GGG ATC CAT ATG CTT AAG TTC AGC GGG T-3'; Coleman et al., 1994). This marker is located between the 5.8S and 28S ribosomal RNA genes, and has been informative for studying the diversity of Symbiodiniaceae (e.g. LaJeunesse, 2001, 2002; LaJeunesse \& Thornhill, 2011; Arif et al., 2014; Boulotte et al., 2016). A unique 8-bp barcode was added to the 5 ' end of each primer for multiplexed amplicon sequencing. In total, 100 sets of tagged primers were used for 90 PCR reactions (triplicates of 30 samples) and 10 notemplate controls. Each reaction mixture comprised a total volume of $25.0 \mu \mathrm{l}$, including $12.5 \mu \mathrm{l}$ GoTaq DNA polymerase (Promega Corporation, USA), $1.0 \mu \mathrm{l} 10 \mu \mathrm{M}$ primers (forward and reverse), $1.0 \mu \mathrm{l}$ DNA template and $9.5 \mu 1$ water. The PCR profile consisted of an initial denaturation of $94^{\circ} \mathrm{C}$ for 180 seconds, following by 35 cycles of $94^{\circ} \mathrm{C}$ for 30 seconds, $55^{\circ} \mathrm{C}$ for 30 seconds and $72^{\circ} \mathrm{C}$ for 45 seconds, and a final extension step of $72^{\circ} \mathrm{C}$ for 180 seconds.

The quality of PCR products was assessed with electrophoresis on a $1 \%$ agarose gel stained with GelRed (Cambridge Bioscience, UK) and visualised under ultraviolet exposure. Gel band intensities were used to approximate normalisation during pooling of amplicons. The pooled library was purified using 1.0 $\times$ Sera-Mag SpeedBeads (GE Healthcare Life Sciences) in 
179

180

181

182

183

184

185

186

187

188

189

190

191

192

193

194

195

196

197

198

199

200

201

202

203

204

205

206

207

208

209

210

211

212

213

214

215

216

217

218

18\% polyethylene glycol (PEG) buffer suspension:DNA ratio and finally eluted with $30 \mu \mathrm{l}$ of water. The amount of DNA post-purification was quantified using a Qubit Fluorometer 3.0 (Life Technologies) and made up to $20 \mathrm{ng} / \mu \mathrm{l}$, with $50 \mu \mathrm{l}$ sent to Axil Scientific Pte Ltd for DNA library preparation using the TruSeq DNA PCR-Free Library Prep Kit (Illumina). Sequencing was carried out in $\sim 50 \%$ of an Illumina MiSeq run, using the Reagent Kit v3 for 300-bp pairedend reads. All sequences generated here are available at the National Center for Biotechnology Information (NCBI; BioProject ID: PRJNA549817).

\section{Data analysis}

The bioinformatics pipeline was based primarily on Sze et al. (2018), Afiq-Rosli et al. (2019) and Lim et al. (2019) (but see Hume et al., 2019). Briefly, Paired-End reAd mergeR (PEAR) (version 0.9.8) (Zhang et al., 2014) was used to assemble paired-end sequences with a default minimum overlap of $10 \mathrm{bp}$; minimum and maximum lengths of 300 and $390 \mathrm{bp}$ respectively, based on the expected amplicon size; and a minimum Phred quality score of 30 to ensure accurate base calls. OBITools (version 1.2.11) (Boyer et al., 2016) were used to process the assembled paired-end reads. Reads were demultiplexed using ngsilter based on the primer sequences, unique tags and sample information to obtain sample sequences. obiuniq collapsed identical sequences and assigned read counts for each unique DNA sequence. obisplit sorted sample data into separate files based on their sample names. Sequences with only a single read were discarded using obigrep. Finally, obiclean was used to identify amplification and sequencing errors by assigning sequence records as 'head' (most common sequence amongst all the sequences), 'internal' (erroneous sequences) and 'singleton' (rare, likely true sequences with no other variants).

Sequences assigned as 'head' were retained for further analysis. No sequences were found in the negative PCR controls following quality checks and filtering.

Sequences were searched against the NCBI $n t$ database using BLAST+ (version 2.3.0; blastn) (Altschul et al., 1990), with maximum E-value of $10^{-6}$ and minimum identity match of $85 \%$. Identity of each sequence was established based on the top match of Symbiodiniaceae type with $\geq 97 \%$ identity, in accordance with previous studies using the ITS2 marker (Arif et al., 2014; Cunning et al., 2017). Following sequence filtering and taxon identification, two endosymbiont community datasets were assembled for subsequent analyses: (1) types with minimum of 10 reads summed across PCR triplicates for each sample; and (2) types present in at least two of the three PCR replicates for each sample. These strict filtering steps would help reduce false positives associated with amplification and sequencing errors. The datasets are available at Zenodo (http://dx.doi.org/10.5281/zenodo.3344613).

The host phylogeny was reconstructed in Huang et al. (2014a) and pruned to show only the coral samples used here (Fig. 1). Briefly, phylogenetic analyses were carried out on the concatenated matrix comprising the nuclear histone H3 (Colgan et al., 1998), internal transcribed spacers 1 and 2 (Takabayashi et al., 1998a, b), and mitochondrial non-coding intergenic region (Fukami et al., 2004a). The maximum likelihood tree was inferred in RAxML 7.7.9 (Stamatakis, 2006; Stamatakis et al., 2008) with 50 random starting trees and 1000 bootstrap replicates. 
219 Bayesian inference was carried out in MrBayes 3.2.2 (Huelsenbeck \& Ronquist, 2001; Ronquist

220

221

222

223

224

225

226

227

228

229

230

231

232

233

234

235

236

237

238

239

240

241

242

243

244

245

246

247

248

249

250

251

252

253

254

255

256

257

\& Huelsenbeck, 2003; Ronquist et al., 2012) with four Markov chains of 6 million generations implemented in two runs, logging one tree per 100 generations and discarding the first 10001 trees as burn-in. Maximum parsimony analysis was performed in PAUP* 4.0b10 (Swofford 2003) with 10000 random additions and 1000 bootstrap replicates.

Endosymbiont data analysis was performed in $\mathrm{R}$ (version 3.4) (R Core Team, 2013) using the vegan package (version 2.4.6) (Oksanen et al., 2013). Variation of Symbiodiniaceae communities among the coral colonies was examined using non-metric multidimensional scaling (NMDS) with the Bray-Curtis dissimilarity_ based on proportional read abundance — and Jaccard distance measures. Analysis of similarities (ANOSIM; 999 permutations) was performed to test for differences in the proportional read abundances of Symbiodiniaceae types among the host coral lineages (A1, A3 and M+S; Fig. 1), host genera (Goniastrea, Merulina and Scapophyllia), and host localities (Australia, Fiji, Singapore and Seychelles), independently. The taxonomic distinctness index was also computed to characterise patterns of Symbiodiniaceae assemblage dissimilarity among host species (Clarke \& Warwick, 1998; Warwick \& Clarke, 2001).

\section{Results \& Discussion}

A total of 10,496,267 reads have been obtained from the MiSeq sequencing run, with 10,119,346 paired-end reads assembled (96.4\%). These reads correspond to 646,568 unique haplotypes. Following error pruning and sequence filtering, 294 haplotypes remain, belonging to three major Symbiodiniaceae genera that are common in Indo-Pacific corals-Symbiodinium (formerly clade A), Cladocopium (formerly clade C) and Durusdinium (formerly clade D) (LaJeunesse et al., 2010a, 2018; Yang et al., 2012).

Cladocopium is overall the most abundant endosymbiont, accounting for $78.2 \%$ of sequences retained, and furthermore the most dominant taxon based on proportional read abundance in six of the eight host species examined (Fig. 2). Cladocopium is present in all host species, while Durusdinium and Symbiodinium are present in six and three host species, respectively. Our results mirror previous community-level studies of Symbiodiniaceae showing that Cladocopium is more abundant in tropical latitudes compared to other clades such as Symbiodinium which is mostly found at higher latitudes (Rodriguez-Lanetty et al., 2001; Savage et al., 2002; Baker, 2003). In particular, endosymbiont communities in corals from the tropical Pacific and Southeast Asian regions appear to be dominated by Cladocopium and, to a lesser extent, Durusdinium (Rodriguez-Lanetty et al., 2001; van Oppen et al., 2001; Baker, 2003; LaJeunesse et al., 2010a; Tanzil et al., 2016). While there are distinct patterns in read abundances of Symbiodiniaceae genera among coral species, proportional read count variance between samples of each host species is large (Fig. 2), revealing large intraspecific variation of endosymbiont abundances. For example, among G. pectinata colonies, Durusdinium reads are on average more abundant than Symbiodinium reads, but Durusdinium is not present in three

Peer) reviewing PDF | (2019:04:36661:1:0:NEW 1 Aug 2019) 
258

259

260

261

262

263

264

265

266

267

268

269

270

271

272

273

274

275

276

277

278

279

280

281

282

283

284

285

286

287

288

289

290

291

292

293

294

295

296

colonies examined. Therefore, at the Symbiodiniaceae genus level, variation among coral colonies within each species may mask differences between species.

Twenty-three Symbiodiniaceae ITS2 types have been found across all colonies, comprising three types from Symbiodinium, eighteen from Cladocopium and two from Durusdinium. Cladocopium goreaui (ITS2 type C1) and Cladocopium C3 are the most common types, present in $32 \%$ and $55 \%$ of all colonies examined. The latter is also present in every merulinid species except Goniastrea minuta, corroborating past studies showing that Cladocopium C3 is a generalist type in the Indo-Pacific (LaJeunesse et al., 2003; Wham et al., 2014), prevalent even in some of the world's warmest reefs (Hume et al., 2013). Similarly, Cladocopium goreaui (ITS2 type C1) is also considered to be a generalist taxon worldwide (LaJeunesse et al., 2003; LaJeunesse, 2005; Wham et al., 2014).

Among the coral species examined here, Goniastrea pectinata and Scapophyllia cylindrica contain the richest Symbiodiniaceae assemblages of 11 and 10 types respectively, with Goniastrea retiformis, Goniastrea favulus and Merulina ampliata following with nine different types. Merulina scabricula only hosts two Symbiodiniaceae types despite being a congener and clustering most closely with M. ampliata (Fig. 1), which has nine types.

Endosymbiont community structure does not differ among host genera $(R=-0.180$, $p=0.979)$ and lineages $(R=0.085, p=0.142$; as defined in Fig. 1$)$ when analysing sequences based on minimum of 10 reads summed across PCR triplicates for each sample (Fig. 3). Results are the same for types present in at least two of the three PCR replicates for each sample $(R=-0.110$, $p=0.792$ for genera; $R=0.110, p=0.146$ for lineages; Fig. S1). Furthermore, no genus- or lineagespecific patterns of endosymbiont-type taxonomic distinctness were apparent among host taxa (Fig. S2). In support, although Goniastrea retiformis and G. minuta are in a lineage distinct from the rest of the species examined (Fig. 1), their endosymbiont communities are neither clustered nor separated from the other species on the NMDS (Fig. 3). Symbiodiniaceae communities does appear to be structured spatially as they are significantly different between Australia, Fiji, Singapore and Seychelles $(R=0.162, p=0.036)$, though this pattern is not significant when considering the types present in at least two of the three PCR replicates $(R=0.054, p=0.313)$. These results should therefore be interpreted with caution.

Host species identity has been shown to play a role in determining endosymbiont community composition (Thornhill et al., 2009, 2014; Tonk et al., 2013). For example, Siderastrea siderea in the Belize Mesoamerican Barrier Reef System contains a distinct Symbiodiniaceae community signal (Baumann et al., 2018). This host specificity reflects various interacting physiological needs of the coral species, such as their depth, light, temperature or nutrient preferences (Finney et al., 2010), and the endosymbiont populations can be further structured according to the environment (Thornhill et al., 2009; Davies et al., 2019).

Interestingly, the host species signal breaks down at the genus level, as Symbiodiniaceae communities in Siderastrea radians are more similar to Pseudodiploria strigosa than its congeneric Siderastrea siderea (Baumann et al., 2018). 
297

298

299

300

301

302

303

304

305

306

307

308

309

310

311

312

313

314

315

316

317

318

319

320

321

322

323

324

325

326

327

328

329

330

331

\section{2}

333

334

335

336

Indeed, various combinations and diversity of endosymbionts allow the holobiont to face distinct environmental stressors (Toller et al., 2001a, b; Berkelmans \& van Oppen, 2006; LaJeunesse et al., 2009). For instance, while the presence of endosymbiotic Cladocopium is associated with large depth ranges and stable growth rates of coral hosts (Little et al., 2004; Cantin et al., 2009), this genus and in particular the supposed generalist Cladocopium C3 can be sensitive to thermal variation at local scales (Keshavmurthy et al., 2012). Therefore, the intraspecific variation in community structure shown in each of the species examined here may be related to environmental differences among host localities (Howells et al., 2012). Because our samples originate from a large spatial range, and since Cladocopium can be found throughout the Indo-Pacific realm (LaJeunesse et al., 2003; Howells et al., 2012; Wham et al., 2014; Wong et al., 2016; Keshavmurthy et al., 2017), our sampling is expected to capture a considerable fraction of the environmental affinities associated with this Symbiodiniaceae genus.

Durusdinium is present in six host species despite being represented by lower read abundance compared with Cladocopium. This is not surprising given that it is the second mostdominant clade behind Cladocopium in the tropical Indo-Pacific (Rodriguez-Lanetty et al., 2001; van Oppen et al., 2001; Baker, 2003; LaJeunesse et al., 2010a; Tanzil et al., 2016). Importantly, Durusdinium is considered an opportunistic taxon, increasing in abundance in hospite during challenging conditions such as coral bleaching, and more generally under extreme or variable levels of heat or light (Toller et al., 2001a; Chen et al., 2003; Lien et al., 2007, 2013). Therefore, the presence and abundance, or absence, of Durusdinium could serve as an indicator of coral community health (Warner et al., 1999; Burnett, 2002; Baker et al., 2004; Reynolds et al., 2008).

The high light tolerance of Durusdinium in shallow water environments may underlie the capacity of colonies living on the reef flat that are often exposed to elevated irradiance levels (see Innis et al., 2018). These corals consist of species such as Goniastrea retiformis, G. minuta and G. pectinata (Huang et al., 2006; Ng et al., 2012) which we have found to host Durusdinium (Fig. 2). Furthermore, this endosymbiont genus tolerates the warmer periods during the MayJune inter-monsoon when the water temperature is in excess of $30^{\circ} \mathrm{C}$ ( $\operatorname{Sin}$ et al., 2016; see Berkelmans, 2002). In more seasonal localities, the summer may bring about the increased dominance of Durusdinium in symbiosis among certain taxa such as Acropora (Chen et al., 2005; Berkelmans \& van Oppen, 2006; Yorifuji et al., 2017), although the degree of symbiont shuffling is affected by each colony's thermal history (Hsu et al., 2012). Here, despite being collected during different time periods throughout the year and over time (Table S1), there are no patterns to suggest discernible seasonality in endosymbiont composition in the merulinids, but further temporal sampling at each study site is needed to uncover any seasonal variations.

\section{Conclusions}

Overall, our results show that Symbiodiniaceae communities are not clustered according to coral host species or genera, and show no discernible patterns based on the host phylogeny. Clearly, intraspecific differences dominate the variation among corals in both endosymbiont community structure and diversity, with no distinct communities hosted by particular coral species or genera.

Peer] reviewing PDF | (2019:04:36661:1:0:NEW 1 Aug 2019) 
337 We posit that the complexity related to horizontal endosymbiont acquisition among the 338 broadcast-spawning coral species examined here could contribute to this (Baird et al., 2009;

339 Hartmann et al., 2017). Even as heritability of symbionts has been shown to be substantial in 340 some species (Quigley et al., 2017), it is not uncommon for a coral host to harbour distinct 341 Symbiodiniaceae communities over its life cycle. For example, juvenile hosts of Acropora corals 342 contain a more diverse Symbiodiniaceae community compared to their adult stage (Cumbo et al., 343 2013; Suzuki et al., 2013; Yamashita et al., 2013). Subsequent dispersal to areas with differing 344 backgrounds of Symbiodiniaceae diversity (Nitschke et al., 2015) may further enhance this 345 complexity as uptake of environmental Symbiodiniaceae or community changes induced under 346 the new conditions could drive shifts in endosymbiotic composition (Quigley et al., 2017). To a 347 limited extent, coral colonies examined here do show consistent patterning of Symbiodiniaceae 348 communities based on their areas of origin. More extensive collections of corals from various 349 regions and environments will help us better understand the specificity of the coral350 endosymbiont relationship.

351 Large-scale spatial structuring of endosymbionts has been hypothesised during the

352

353

354

355

356

357

358

359

360

361

362

363

364

365

366

367

368

369

370

371

372

373

374

375 earliest stages of such research (Baker \& Rowan, 1997; Rowan, 1998) and also demonstrated in studies across a diverse range of invertebrates (LaJeunesse et al., 2004; Gong et al., 2018). Today, even with the application of new sequencing technologies that confer higher sensitivity for detecting Symbiodiniaceae types, the resolution of spatial patterns remains rough due to sparse sampling. Certainly, a concerted sampling effort at more reef localities will help verify our findings and provide new insights into the distribution and biogeography of this vital symbiosis.

\section{Acknowledgements}

Computational work was partially performed with resources from the National Supercomputing Centre, Singapore (https://www.nscc.sg).

\section{References}

Afiq-Rosli L, Huang D, Toh TC, Taira D, Ng CSL, Song T, Chou LM (2019) Maximising genetic diversity during coral transplantation from a highly impacted source reef. Conserv Genet 20: 629-637

Altschul SF, Gish W, Miller W, Myers EW, Lipman DJ (1990) Basic local alignment search tool. J Mol Biol 215: 403-410

Arif C, Daniels C, Bayer T, Banguera-Hinestroza E, Barbrook A, Howe CJ, et al. (2014) Assessing Symbiodinium diversity in scleractinian corals via next-generation sequencingbased genotyping of the ITS2 rDNA region. Mol Ecol 23: 4418-4433

Arrigoni R, Stefani F, Pichon M, Galli P, Benzoni F (2012) Molecular phylogeny of the Robust clade (Faviidae, Mussidae, Merulinidae, and Pectiniidae): an Indian Ocean perspective. Mol Phylogenet Evol 65: 183-193 
376

377

378

379

380

381

382

383

384

385

386

387

388

389

390

391

392

393

394

395

396

397

398

399

400

401

402

403

404

405

406

407

408

409

410

411

412

413

414

Baird AH, Guest JR, Willis BL (2009) Systematic and biogeographical patterns in the reproductive biology of scleractinian corals. Annu Rev Ecol Evol Syst 40: 551-571

Baker AC (2003) Flexibility and specificity in coral-algal symbiosis: diversity, ecology, and biogeography of Symbiodinium. Annu Rev Ecol Evol Syst 34: 661-689

Baker AC, Rowan R (1997) Diversity of symbiotic dinoflagellates (zooxanthellae) in scleractinian corals of the Caribbean and eastern Pacific. Proc 8th Int Coral Reef Symp 2: 1301-1306

Baker AC, Starger CJ, McClanahan TR, Glynn PW (2004) Corals' adaptive response to climate change. Nature 430: 741-741

Baumann JH, Davies SW, Aichelman HE, Castillo KD (2018) Coral Symbiodinium community composition across the Belize Mesoamerican Barrier Reef System is influenced by host species and thermal variability. Microb Ecol 75: 903-915

Benzoni F, Arrigoni R, Stefani F, Pichon M (2011) Phylogeny of the coral genus Plesiastrea (Cnidaria, Scleractinia). Contrib. Zool. 80: 231-249

Berkelmans R (2002) Time-integrated thermal bleaching thresholds of reefs and their variation on the Great Barrier Reef. Mar Ecol Prog Ser 229: 73-82

Berkelmans R, van Oppen MJH (2006) The role of zooxanthellae in the thermal tolerance of corals: a "nugget of hope" for coral reefs in an era of climate change. Proc R Soc B-Biol Sci 273: 2305-2312

Bhattacharya D, Agrawal S, Aranda M, Baumgarten S, Belcaid M, Drake JL, et al. (2016) Comparative genomics explains the evolutionary success of reef-forming corals. eLife 5: e13288

Bongaerts P, Riginos C, Hay KB, van Oppen MJH, Hoegh-Guldberg O, Dove S (2011) Adaptive divergence in a scleractinian coral: physiological adaptation of Seriatopora hystrix to shallow and deep reef habitats. BMC Evol Biol 11: 303.

Bongaerts P, Riginos C, Ridgway T, Sampayo EM, van Oppen MJH, Englebert N, Vermeulen F, Hoegh-Guldberg O (2010) Genetic divergence across habitats in the widespread coral Seriatopora hystrix and its associated Symbiodinium. PLoS ONE 5: e10871

Boulotte NM, Dalton SJ, Carroll AG, Harrison PL, Putnam HM, Peplow LM, et al. (2016) Exploring the Symbiodinium rare biosphere provides evidence for symbiont switching in reef-building corals. ISME J 10: 2693-2701

Boyer F, Mercier C, Bonin A, Le Bras Y, Taberlet P, Coissac E (2016) OBITOOLS: a UNIXinspired software package for DNA metabarcoding. Mol Ecol Resour 16: 176-182

Brener-Raffalli K, Clerissi C, Vidal-Dupiol J, Adjeroud M, Bonhomme F, Pratlong M, et al. (2018) Thermal regime and host clade, rather than geography, drive Symbiodinium and bacterial assemblages in the scleractinian coral Pocillopora damicornis sensu lato. Microbiome 6: 39

Budd AF, Stolarski J (2011) Corallite wall and septal microstructure in scleractinian reef corals: Comparison of molecular clades within the family Faviidae. J Morphol 272: 66-88 
415 Budd AF, Romano SL, Smith ND, Barbeitos MS (2010) Rethinking the phylogeny of 416 scleractinian corals: a review of morphological and molecular data. Integr Comp Biol 50: $417 \quad 411-427$

418 Budd AF, Fukami H, Smith ND, Knowlton N (2012) Taxonomic classification of the reef coral 419

420

421

422

423

424

425

426

427

428

429

430

431

432

433

434

435

436

437

438

439

440

441

442

443

444

445

446

447

448

449

450

451

452

453 family Mussidae (Cnidaria: Anthozoa: Scleractinia). Zool J Linn Soc 166: 465-529

Burnett WJ (2002) Longitudinal variation in algal symbionts (zooxanthellae) from the Indian Ocean zoanthid Palythoa caesia. Mar Ecol Prog Ser 234: 105-109

Cairns SD (2001) A generic revision and phylogenetic analysis of the Dendrophylliidae (Cnidaria: Scleractinia). Smithsonian Contrib Zool 615: 1-75

Cantin NE, van Oppen MJH, Willis BL, Mieog JC, Negri AP (2009) Juvenile corals can acquire more carbon from high-performance algal symbionts. Coral Reefs 28: 405-414

Chen CA, Lam KKY, Nakano Y, Tsai W-S (2003) A stable association of the stress-tolerant zooxanthellae, Symbiodinium clade D, with the low-temperature-tolerant coral, Oulastrea crispata (Scleractinia: Faviidae) in subtropical non-reefal coral communities. Zool Stud 42: $540-550$

Chen CA, Wang J-T, Fang L-S, Yang Y-W (2005) Fluctuating algal symbiont communities in Acropora palifera (Scleractinia: Acroporidae) from Taiwan. Mar Ecol Prog Ser 295: $113-121$

Clarke KR, Warwick RM (1998) A taxonomic distinctness index and its statistical properties. J Appl Ecol 35: 523-531

Coleman AW, Suarez A, Goff LJ (1994) Molecular delineation of species and syngens in volvocacean green algae (Chlorophyta). J Phycol 30: 80-90

Colgan DJ, McLauchlan A, Wilson GDF, Livingston SP, Edgecombe GD, Macaranas J, Cassis G, Gray MR (1998) Histone H3 and U2 snRNA DNA sequences and arthropod molecular evolution. Aust J Zool 46: 419-437

Cooper TF, Berkelmans R, Ulstrup KE, Weeks S, Radford B, Jones AM, et al. (2011) Environmental factors controlling the distribution of Symbiodinium harboured by the coral Acropora millepora on the Great Barrier Reef. PLoS ONE 6: e25536

Cumbo VR, Baird AH, van Oppen MJH (2013) The promiscuous larvae: flexibility in the establishment of symbiosis in corals. Coral Reefs 32: 111-120

Cunning R, Gates RD, Edmunds PJ (2017) Using high-throughput sequencing of ITS2 to describe Symbiodinium metacommunities in St. John, US Virgin Islands. PeerJ 5: e3472

Davies SW, Wham DC, Kanke MR, Matz MV (2019) Contrasting population genetic structure in Acropora coral hosts and their algal symbionts across multiple spatial scales. bioRxiv 575183. doi:10.1101/575183

Finney JC, Pettay DT, Sampayo EM, Warner ME, Oxenford HA, LaJeunesse TC (2010) The relative significance of host-habitat, depth, and geography on the ecology, endemism, and speciation of coral endosymbionts in the genus Symbiodinium. Microb Ecol 60: 250263 
454 Fisher R, O'Leary RA, Low-Choy S, Mengersen K, Knowlton N, Brainard RE, Caley MJ (2015)

455

456

457

458

459

460

461

462

463

464

465

466

467

468

469

470

471

472

473

474

475

476

477

478

479

480

481

482

483

484

485

486

487

488

489

490

491

492

Species richness on coral reefs and the pursuit of convergent global estimates. Curr Biol 25: 500-505

Flot J-F, Blanchot J, Charpy L, Cruaud C, Licuanan WY, Nakano Y, et al. (2011) Incongruence between morphotypes and genetically delimited species in the coral genus Stylophora: phenotypic plasticity, morphological convergence, morphological stasis or interspecific hybridization? BMC Ecol 11: 22

Frank U, Mokady O (2002) Coral biodiversity and evolution: recent molecular contributions. Can J Zool 80: 1723-1734

Fukami H (2008) Short review: molecular phylogenetic analyses of reef corals. Galaxea 10: 4755

Fukami H, Budd AF, Levitan DR, Jara J, Kersanach R, Knowlton N (2004a) Geographic differences in species boundaries among members of the Montastraea annularis complex based on molecular and morphological markers. Evolution 58: 324-337

Fukami H, Budd AF, Paulay G, Solé-Cava A, Chen CA, Iwao K, et al. (2004b) Conventional taxonomy obscures deep divergence between Pacific and Atlantic corals. Nature 427: 832-835

Fukami H, Chen CA, Budd AF, Collins A, Wallace C, Chuang Y-Y, et al. (2008) Mitochondrial and nuclear genes suggest that stony corals are monophyletic but most families of stony corals are not (Order Scleractinia, Class Anthozoa, Phylum Cnidaria). PLoS ONE 3: e3222

Gong S, Chai G, Xiao Y, Xu L, Yu K-F, Li J, et al. (2018) Flexible symbiotic associations of Symbiodinium with five typical coral species in tropical and subtropical reef regions of the northern South China Sea. Front Microbiol 9: 2485

Goulet TL (2006) Most corals may not change their symbionts. Mar Ecol Prog Ser 321: 1-7

Hartmann AC, Baird AH, Knowlton N, Huang D (2017) The paradox of environmental symbiont acquisition in obligate mutualisms. Curr Biol 27: 3711-3716

Howells EJ, Beltran VH, Larsen NW, Bay LK, Willis BL, van Oppen MJH (2012) Coral thermal tolerance shaped by local adaptation of photosymbionts. Nat Clim Change 2: 116-120

Hsu C-M, Keshavmurthy S, Denis V, Kuo C-Y, Wang J-T, Meng P-J, et al. (2012) Temporal and spatial variations in symbiont communities of catch bowl coral Isopora palifera (Scleractinia: Acroporidae) on reefs in Kenting National Park, Taiwan. Zool. Stud. 51:1343-1353

Huang D (2012) Threatened reef corals of the world. PLoS ONE 7: e34459

Huang D, Roy K (2013) Anthropogenic extinction threats and future loss of evolutionary history in reef corals. Ecol Evol 3: 1184-1193

Huang D, Chou LM, Todd PA, Ang KH, Boon PY, Cheng L (2006) Algal and invertebrate diversity of the intertidal zone at Labrador Nature Reserve, Singapore. Malayan Nat J 59: 93-102

Peer) reviewing PDF | (2019:04:36661:1:0:NEW 1 Aug 2019) 
493

494

495

496

497

498

499

500

501

502

503

504

505

506

507

508

509

510

511

512

513

514

515

516

517

518

519

520

521

522

523

524

525

526

527

528

529

530

Huang D, Meier R, Todd PA, Chou LM (2008) Slow mitochondrial COI sequence evolution at the base of the metazoan tree and its implications for DNA barcoding. J Mol Evol 66: 167-174

Huang D, Meier R, Todd PA, Chou LM (2009) More evidence for pervasive paraphyly in scleractinian corals: systematic study of Southeast Asian Faviidae (Cnidaria; Scleractinia) based on molecular and morphological data. Mol Phylogenet Evol 50: 102-116

Huang D, Licuanan WY, Baird AH, Fukami H (2011) Cleaning up the "Bigmessidae": molecular phylogeny of scleractinian corals from Faviidae, Merulinidae, Pectiniidae and Trachyphylliidae. BMC Evol Biol 11: 37

Huang D, Benzoni F, Arrigoni R, Baird AH, Berumen ML, Bouwmeester J, et al. (2014a) Towards a phylogenetic classification of reef corals: the Indo-Pacific genera Merulina, Goniastrea and Scapophyllia (Scleractinia, Merulinidae). Zool Scr 43: 531-548

Huang D, Benzoni F, Fukami H, Knowlton N, Smith ND, Budd AF (2014b) Taxonomic classification of the reef coral families Merulinidae, Montastraeidae, and Diploastraeidae (Cnidaria: Anthozoa: Scleractinia). Zool J Linn Soc 171: 277-355

Huelsenbeck JP, Ronquist F (2001) MRBAYES: Bayesian inference of phylogenetic trees. Bioinformatics 17: 754-755

Hume B, D'Angelo C, Burt J, Baker AC, Riegl BM, Wiedenmann J (2013) Corals from the Persian/Arabian Gulf as models for thermotolerant reef-builders: Prevalence of clade C3 Symbiodinium, host fluorescence and ex situ temperature tolerance. Mar Pollut Bull 72: 313-322

Hume BCC, Smith EG, Ziegler M, Warrington HJM, Burt JA, LaJeunesse TC, Wiedenmann J, Voolstra CR (2019) SymPortal: a novel analytical framework and platform for coral algal symbiont next-generation sequencing ITS2 profiling. Mol Ecol Resour 19: 1063-1080

Innis T, Cunning R, Ritson-Williams R, Wall CB, Gates RD (2018) Coral color and depth drive symbiosis ecology of Montipora capitata in Kane'ohe Bay, O‘ahu, Hawai'i. Coral Reefs 37: 423-430

Jones AM, Berkelmans R, van Oppen MJH, Mieog JC, Sinclair W (2008) A community change in the algal endosymbionts of a scleractinian coral following a natural bleaching event: field evidence of acclimatization. Proc R Soc B-Biol Sci 275: 1359-1365

Kemp DW, Hernandez-Pech X, Iglesias-Prieto R, Fitt WK, Schmidt GW (2014) Community dynamics and physiology of Symbiodinium spp. before, during, and after a coral bleaching event. Limnol Oceanogr 59: 788-797

Kerr AM, Baird AH, Hughes TP (2011) Correlated evolution of sex and reproductive mode in corals (Anthozoa: Scleractinia). Proc R Soc B-Biol Sci 278: 75-81

Keshavmurthy S, Hsu C-M, Kuo C-Y, Meng P-J, Wang J-T, Chen CA (2012) Symbiont communities and host genetic structure of the brain coral Platygyra verweyi, at the outlet of a nuclear power plant and adjacent areas. Mol Ecol 21: 4393-4407

Peer] reviewing PDF | (2019:04:36661:1:0:NEW 1 Aug 2019) 
531 Keshavmurthy S, Tang K-H, Hsu C-M, Gan C-H, Kuo C-Y, Soong K, et al. (2017)

532

533

534

535

536

537

538

539

540

541

542

543

544

545

546

547

548

549

550

551

552

553

554

555

556

557

558

559

560

561

562

563

564

565

566

567

568

569

570

Symbiodinium spp. associated with scleractinian corals from Dongsha Atoll (Pratas),

Taiwan, in the South China Sea. PeerJ 5: e2871

Kitahara MV, Cairns SD, Stolarski J, Blair D, Miller DJ (2010) A comprehensive phylogenetic analysis of the Scleractinia (Cnidaria, Anthozoa) based on mitochondrial CO1 sequence data. PLoS ONE 5: e11490

Kitahara MV, Fukami H, Benzoni F, Huang D (2016) The new systematics of Scleractinia: integrating molecular and morphological evidence. In "The Cnidaria, Past, Present and Future”. Ed by S Goffredo, Z Dubinsky, Springer International Publishing, Cham, pp 4159

LaJeunesse TC (2001) Investigating the biodiversity, ecology, and phylogeny of endosymbiotic dinoflagellates in the genus Symbiodinium using the ITS region: in search of a "species" level marker. J Phycol 37: 866-880

LaJeunesse TC (2002) Diversity and community structure of symbiotic dinoflagellates from Caribbean coral reefs. Mar Biol 141: 387-400

LaJeunesse TC (2005) "Species" radiations of symbiotic dinoflagellates in the Atlantic and IndoPacific since the Miocene-Pliocene transition. Mol Biol Evol 22: 570-581

LaJeunesse TC, Thornhill DJ (2011) Improved resolution of reef-coral endosymbiont (Symbiodinium) species diversity, ecology, and evolution through psbA non-coding region genotyping. PLoS ONE 6: e29013

LaJeunesse TC, Trench RK (2000) Biogeography of two species of Symbiodinium (Freudenthal) inhabiting the intertidal sea anemone Anthopleura elegantissima (Brandt). Biol Bull 199:126-134

LaJeunesse TC, Loh WKW, van Woesik R, Hoegh-Guldberg O, Schmidt GW, Fitt WK (2003) Low symbiont diversity in southern Great Barrier Reef corals, relative to those of the Caribbean. Limnol Oceanogr 48: 2046-2054

LaJeunesse TC, Bhagooli R, Hidaka M, DeVantier L, Done T, Schmidt GW, et al. (2004) Closely related Symbiodinium spp. differ in relative dominance in coral reef host communities across environmental, latitudinal and biogeographic gradients. Mar Ecol Prog Ser 284: 147-161

LaJeunesse TC, Smith RT, Finney J, Oxenford H (2009) Outbreak and persistence of opportunistic symbiotic dinoflagellates during the 2005 Caribbean mass coral "bleaching” event. Proc R Soc B-Biol Sci 276: 4139-4148

LaJeunesse TC, Pettay DT, Sampayo EM, Phongsuwan N, Brown B, Obura DO, et al. (2010a) Long-standing environmental conditions, geographic isolation and host-symbiont specificity influence the relative ecological dominance and genetic diversification of coral endosymbionts in the genus Symbiodinium. J Biogeogr 37: 785-800

LaJeunesse TC, Smith R, Walther M, Pinzon J, Pettay DT, McGinley MP, et al. (2010b) Hostsymbiont recombination versus natural selection in the response of coral-dinoflagellate symbioses to environmental disturbance. Proc R Soc B-Biol Sci 277: 2925-2934

Peer] reviewing PDF | (2019:04:36661:1:0:NEW 1 Aug 2019) 
571 LaJeunesse TC, Wham DC, Pettay DT, Parkinson JE, Keshavmurthy S, Chen CA (2014)

572 Ecologically differentiated stress-tolerant endosymbionts in the dinoflagellate genus

573 Symbiodinium (Dinophyceae) Clade D are different species. Phycologia 53: 305-319

574 LaJeunesse TC, Parkinson JE, Gabrielson PW, Jeong HJ, Reimer JD, Voolstra CR, Santos SR

575 (2018) Systematic revision of Symbiodiniaceae highlights the antiquity and diversity of $576 \quad$ coral endosymbionts. Curr Biol 28: 2570-2580

577 Lien Y-T, Nakano Y, Plathong S, Fukami H, Wang J-T, Chen CA (2007) Occurrence of the

578 putatively heat-tolerant Symbiodinium phylotype D in high-latitudinal outlying coral

$579 \quad$ communities. Coral Reefs 26: 35-44

580 Lien Y-T, Keshavmurthy S, Nakano Y, Plathong S, Huang H, Hsu C-M, et al. (2013) Host

581

582

583

584

585

586

587

588

589

590

591

592

593

594

595

596

597

598

599

600

601

602

603

604

605

606

607

608

609 genetics and Symbiodinium D diversity in a stress-tolerant scleractinian coral, Oulastrea crispata, in the West Pacific. Mar Ecol Prog Ser 473: 163-177

Lim SSQ, Huang D, Soong K, Neo ML (2019) Diversity of endosymbiotic Symbiodiniaceae in giant clams at Dongsha Atoll, northern South China Sea. Symbiosis 78: 251-262

Little AF, van Oppen MJH, Willis BL (2004) Flexibility in algal endosymbioses shapes growth in reef corals. Science 304: 1492-1494

Loh W, Carter D, Hoegh-Guldberg O (1998) Diversity of zooxanthellae from scleractinian corals of One Tree Island (The Great Barrier Reef). In "Proceedings of the Australian Coral Reef Society 75th Anniversary Conference, Heron Island, October 1997" School of Marine Science, The University of Queensland, Brisbane, pp 87-95

Madin JS, Anderson KD, Andreasen MH, Bridge TCL, Cairns SD, Connolly SR, et al. (2016a) The Coral Trait Database, a curated database of trait information for coral species from the global oceans. Sci Data 3: 160017

Madin JS, Hoogenboom MO, Connolly SR, Darling ES, Falster DS, Huang D, et al. (2016b) A trait-based approach to advance coral reef science. Trends Ecol Evol 31: 419-428

Muscatine L, Cernichiari E (1969) Assimilation of photosynthetic products of zooxanthellae by a reef coral. Biol Bull 137: 506-523

Muscatine L, Porter JW (1977) Reef corals: mutualistic symbioses adapted to nutrient-poor environments. BioScience 27: 454-460

Ng CSL, Chen D, Chou LM (2012) Hard coral assemblages on seawalls in Singapore. In Singapore, pp 75-79

Nitschke MR, Davy SK, Ward S (2016) Horizontal transmission of Symbiodinium cells between adult and juvenile corals is aided by benthic sediment. Coral Reefs 35: 335-344

Oksanen J, Blanchet FG, Kindt R, Legendre P, Minchin PR, O'Hara RB, et al. (2013) vegan: Community Ecology Package. R Package Version 2.0-8

Quek ZBR, Huang D (2019) Effects of missing data and data type on phylotranscriptomic analysis of stony corals (Cnidaria: Anthozoa: Scleractinia). Mol Phylogenet Evol 134: $12-23$ 
610 Quigley KM, Davies SW, Kenkel CD, Willis BL, Matz MV, Bay LK (2014) Deep-sequencing

611

612

613

614

615

616

617

618

619

620

621

622

623

624

625

626

627

628

629

630

631

632

633

634

635

636

637

638

639

640

641

642

643

644

645

646

647 method for quantifying background abundances of Symbiodinium types: exploring the rare Symbiodinium biosphere in reef-building corals. PLoS ONE 9: e94297

Quigley KM, Willis BL, Bay LK (2017) Heritability of the Symbiodinium community in vertically- and horizontally-transmitting broadcast spawning corals. Sci Rep 7: 8219

R Core Team (2013) R: A Language and Environment for Statistical Computing. R Foundation for Statistical Computing, Vienna, Austria

Reaka-Kudla ML (1997) The global biodiversity of coral reefs: a comparison with rain forests. In "Biodiversity II: Understanding and Protecting Our Biological Resources" Ed by ML Reaka-Kudla, DE Wilson, EO Wilson, Joseph Henry Press, Washington, DC, pp 83-108

Reynolds JM, Bruns BU, Fitt WK, Schmidt GW (2008) Enhanced photoprotection pathways in symbiotic dinoflagellates of shallow-water corals and other cnidarians. Proc Natl Acad Sci USA 105: 13674-13678

Rodriguez-Lanetty M, Loh W, Carter D, Hoegh-Guldberg O (2001) Latitudinal variability in symbiont specificity within the widespread scleractinian coral Plesiastrea versipora. Mar Biol 138: 1175-1181

Ronquist F, Huelsenbeck JP (2003) MrBayes 3: Bayesian phylogenetic inference under mixed models. Bioinformatics 19: 1572-1574

Ronquist F, Teslenko M, van der Mark P, Ayres DL, Darling A, Höhna S, Larget B, Liu L, Suchard MA, Huelsenbeck JP (2012) MrBayes 3.2: Efficient Bayesian phylogenetic inference and model choice across a large model space. Syst Biol 61: 539-542

Rowan R (1998) Diversity and ecology of zooxanthellae on coral reefs. J Phycol 34: 407-417

Rowan R (2004) Thermal adaptation in reef coral symbionts. Nature 430: 742

Rowan R, Knowlton N (1995) Intraspecific diversity and ecological zonation in coral-algal symbiosis. Proc Natl Acad Sci USA 92: 2850-2853

Rowan R, Powers DA (1991a) A molecular genetic classification of zooxanthellae and the evolution of animal-algal symbioses. Science 251: 1348-1351

Rowan R, Powers DA (1991b) Molecular genetic identification of symbiotic dinoflagellates (zooxanthellae). Mar Ecol Prog Ser 71: 65-73

Sampayo EM, Ridgway T, Bongaerts P, Hoegh-Guldberg O (2008) Bleaching susceptibility and mortality of corals are determined by fine-scale differences in symbiont type. Proc Natl Acad Sci USA 105: 10444-10449

Sargent TD, Jamrich M, Dawid IB (1986) Cell interactions and the control of gene activity during early development of Xenopus laevis. Dev Biol 114: 238-246

Savage AM, Goodson MS, Visram S, Trapido-Rosenthal H, Wiedenmann J, Douglas AE (2002) Molecular diversity of symbiotic algae at the latitudinal margins of their distribution: dinoflagellates of the genus Symbiodinium in corals and sea anemones. Mar Ecol Prog Ser 244: 17-26 
648 Sawall Y, Al-Sofyani A, Banguera-Hinestroza E, Voolstra CR (2014) Spatio-temporal analyses

649

650

651

652

653

654

655

656

657

658

659

660

661

662

663

664

665

666

667

668

669

670

671

672

673

674

675

676

677

678

679

680

681

682

683

684

685 of Symbiodinium physiology of the coral Pocillopora verrucosa along large-scale nutrient and temperature gradients in the Red Sea. PLoS ONE 9: e103179

Silverstein RN, Cunning R, Baker AC (2015) Change in algal symbiont communities after bleaching, not prior heat exposure, increases heat tolerance of reef corals. Glob Change Biol 21: 236-249

Sin TM, Ang HP, Buurman J, Lee AC, Leong YL, Ooi SK, et al. (2016) The urban marine environment of Singapore. Reg Stud Mar Sci 8: 331-339

Smith EG, Ketchum RN, Burt JA (2017a) Host specificity of Symbiodinium variants revealed by an ITS2 metahaplotype approach. ISME J 11: 1500-1503

Smith EG, Vaughan GO, Ketchum RN, McParland D, Burt JA (2017b) Symbiont community stability through severe coral bleaching in a thermally extreme lagoon. Sci Rep 7: 2428

Stamatakis A (2006) RAxML-VI-HPC: Maximum likelihood-based phylogenetic analyses with thousands of taxa and mixed models. Bioinformatics 22: 2688-2690

Stamatakis A, Hoover P, Rougemont J (2008) A rapid bootstrap algorithm for the RAxML web servers. Syst Biol 57: 758-771

Stat M, Carter DA, Hoegh-Guldberg O (2006) The evolutionary history of Symbiodinium and scleractinian hosts - Symbiosis, diversity, and the effect of climate change. Perspect Plant Ecol Evol Syst 8: 23-43

Swofford DL (2003) PAUP*. Phylogenetic Analysis Using Parsimony (*and Other Methods). Version 4

Suzuki G, Yamashita H, Kai S, Hayashibara T, Suzuki K, Iehisa Y, et al. (2013) Early uptake of specific symbionts enhances the post-settlement survival of Acropora corals. Mar Ecol Prog Ser 494: 149-158

Sze Y, Miranda LN, Sin TM, Huang D (2018) Characterising planktonic dinoflagellate diversity in Singapore using DNA metabarcoding. Metabarcoding Metagenomics 2: e25136

Takabayashi M, Carter DA, Loh WKW, Hoegh-Guldberg O (1998a) A coral-specific primer for PCR amplification of the internal transcribed spacer region in ribosomal DNA. Mol Ecol 7: $928-930$

Takabayashi M, Carter DA, Ward S, Hoegh-Guldberg O (1998b) Inter- and intra-specific variability in ribosomal DNA sequence in the internal transcribed spacer region of corals. Proceedings of the Australian Coral Reef Society 75th Anniversary Conference 241-248

Tanzil JTI, Ng PKA, Tey YQ, Tan HYB, Yun YE, Huang D (2016) A preliminary characterisation of Symbiodinium diversity in some common corals from Singapore. COSMOS 12: 15-27

Thomas L, Kendrick GA, Kennington WJ, Richards ZT, Stat M (2014) Exploring Symbiodinium diversity and host specificity in Acropora corals from geographical extremes of Western Australia with 454 amplicon pyrosequencing. Mol Ecol 23: 3113-3126 
686 Thornhill DJ, Xiang Y, Fitt WK, Santos SR (2009) Reef endemism, host specificity and temporal

687

688

689

690

691

692

693

694

695

696

697

698

699

700

701

702

703

704

705

706

707

708

709

710

711

712

713

714

715

716

717

718

719

720

721

722

723

724

725 stability in populations of symbiotic dinoflagellates from two ecologically dominant Caribbean corals. PLoS ONE 4: e6262

Thornhill DJ, Lewis AM, Wham DC, LaJeunesse TC (2014) Host-specialist lineages dominate the adaptive radiation of reef coral endosymbionts. Evolution 68: 352-367

Toller WW, Rowan R, Knowlton N (2001a) Repopulation of zooxanthellae in the Caribbean corals Montastraea annularis and M. faveolata following experimental and diseaseassociated bleaching. Biol Bull 201: 360-373

Toller WW, Rowan R, Knowlton N (2001b) Zooxanthellae of the Montastraea annularis species complex: patterns of distribution of four taxa of Symbiodinium on different reefs and across depths. Biol Bull 201: 348-359

Tonk L, Bongaerts P, Sampayo EM, Hoegh-Guldberg O (2013) SymbioGBR: a web-based database of Symbiodinium associated with cnidarian hosts on the Great Barrier Reef. BMC Ecol 13: 7

van Oppen MJH, Palstra FP, Piquet AMT, Miller DJ (2001) Patterns of coral-dinoflagellate associations in Acropora: significance of local availability and physiology of Symbiodinium strains and host-symbiont selectivity. Proc R Soc Lond B-Biol Sci 268: 1759-1767

Veron JEN (2000) Corals of the World. Australian Institute of Marine Science, Townsville Warner ME, Fitt WK, Schmidt GW (1996) The effects of elevated temperature on the photosynthetic efficiency of zooxanthellae in hospite from four different species of reef coral: a novel approach. Plant Cell Environ 19: 291-299

Warner ME, Fitt WK, Schmidt GW (1999) Damage to photosystem II in symbiotic dinoflagellates: A determinant of coral bleaching. Proc Natl Acad Sci USA 96: 80078012

Warwick RM, Clarke KR (2001) Practical measures of marine biodiversity based on relatedness of species. Oceanogr Mar Biol 39: 207-231

Weis VM, Reynolds WS, deBoer MD, Krupp DA (2001) Host-symbiont specificity during onset of symbiosis between the dinoflagellates Symbiodinium spp. and planula larvae of the scleractinian coral Fungia scutaria. Coral Reefs 20: 301-308

Wham DC, Carmichael M, LaJeunesse TC (2014) Microsatellite loci for Symbiodinium goreaui and other Clade C Symbiodinium. Conserv Genet Resour 6:127-129

Wong JCY, Thompson P, Xie JY, Qiu J-W, Baker DM (2016) Symbiodinium clade C generality among common scleractinian corals in subtropical Hong Kong. Reg Stud Mar Sci 8: 439444

Yamashita H, Suzuki G, Hayashibara T, Koike K (2013) Acropora recruits harbor "rare" Symbiodinium in the environmental pool. Coral Reefs 32: 355-366

Yang S-Y, Keshavmurthy S, Obura D, Sheppard CRC, Visram S, Chen CA (2012) Diversity and distribution of Symbiodinium associated with seven common coral species in the Chagos Archipelago, central Indian Ocean. PLoS ONE 7: e35836

Peer) reviewing PDF | (2019:04:36661:1:0:NEW 1 Aug 2019) 
726 Yellowlees D, Rees TAV, Leggat W (2008) Metabolic interactions between algal symbionts and 727 invertebrate hosts. Plant Cell Environ 31: 679-694

728 Yorifuji M, Harii S, Nakamura R, Fudo M (2017) Shift of symbiont communities in Acropora 729 tenuis juveniles under heat stress. PeerJ 5: e4055

730 Zhang J, Kobert K, Flouri T, Stamatakis A (2014) PEAR: a fast and accurate Illumina Paired$731 \quad$ End reAd mergeR. Bioinformatics 30: 614-620

732 


\section{Figures \& Tables}

734 Figure 1. Molecular phylogenetic tree of Merulinidae corals. Phylogeny based on Huang et

735 al. (2014a). Nodes at least moderately supported, with maximum likelihood and parsimony

736 bootstrap $>60$ and Bayesian posterior probability $>0.95$, are labelled with circles. Host clades A1

737 and A3 follow the previous study, and are tested for differences in Symbiodiniaceae

738 communities with Merulina + Scapophyllia (clade M+S).

739

740

Figure 2. Proportional abundance of sequencing reads recovered. MiSeq sequencing data for

741 each Symbiodiniaceae genus among coral species examined.

742

743

Figure 3. Non-metric multidimensional scaling of Symbiodiniaceae communities. Analysis

744 of endosymbiont communities in Merulinidae corals based on the Bray-Curtis dissimilarity (top; stress $=0.097$ ) and Jaccard distance (bottom; stress=0.093) measures of symbiont types with $\geq 10$

746 reads in each colony. Symbols are distinguished according to host species and locality.

747

748

Figure S1. Non-metric multidimensional scaling of Symbiodiniaceae communities. Analysis

749 of endosymbiont communities in Merulinidae corals based on the Bray-Curtis dissimilarity (top;

750 stress $=0.081$ ) and Jaccard distance (bottom; stress $=0.098$ ) measures of symbiont types detected

751 in at least two of three polymerase chain reactions (each $\geq 2$ reads). Symbols are distinguished

752 according to host species and locality.

753

754

Figure S2. Taxonomic distinctness of Symbiodiniaceae communities. Analysis of

755 endosymbiont communities in Merulinidae species based on the taxonomic distinctness index (Clarke \& Warwick, 1998; Warwick \& Clarke, 2001).

757

Table S1. Collection data for coral samples examined in this study.

759 


\section{Figure 1}

Molecular phylogenetic tree of Merulinidae corals.

Phylogeny based on Huang et al. (2014a). Nodes at least moderately supported, with maximum likelihood and parsimony bootstrap $>60$ and Bayesian posterior probability $>0.95$, are labelled with circles. Host clades A1 and A3 follow the previous study, and are tested for differences in Symbiodiniaceae communities with Merulina + Scapophyllia (clade M+S).

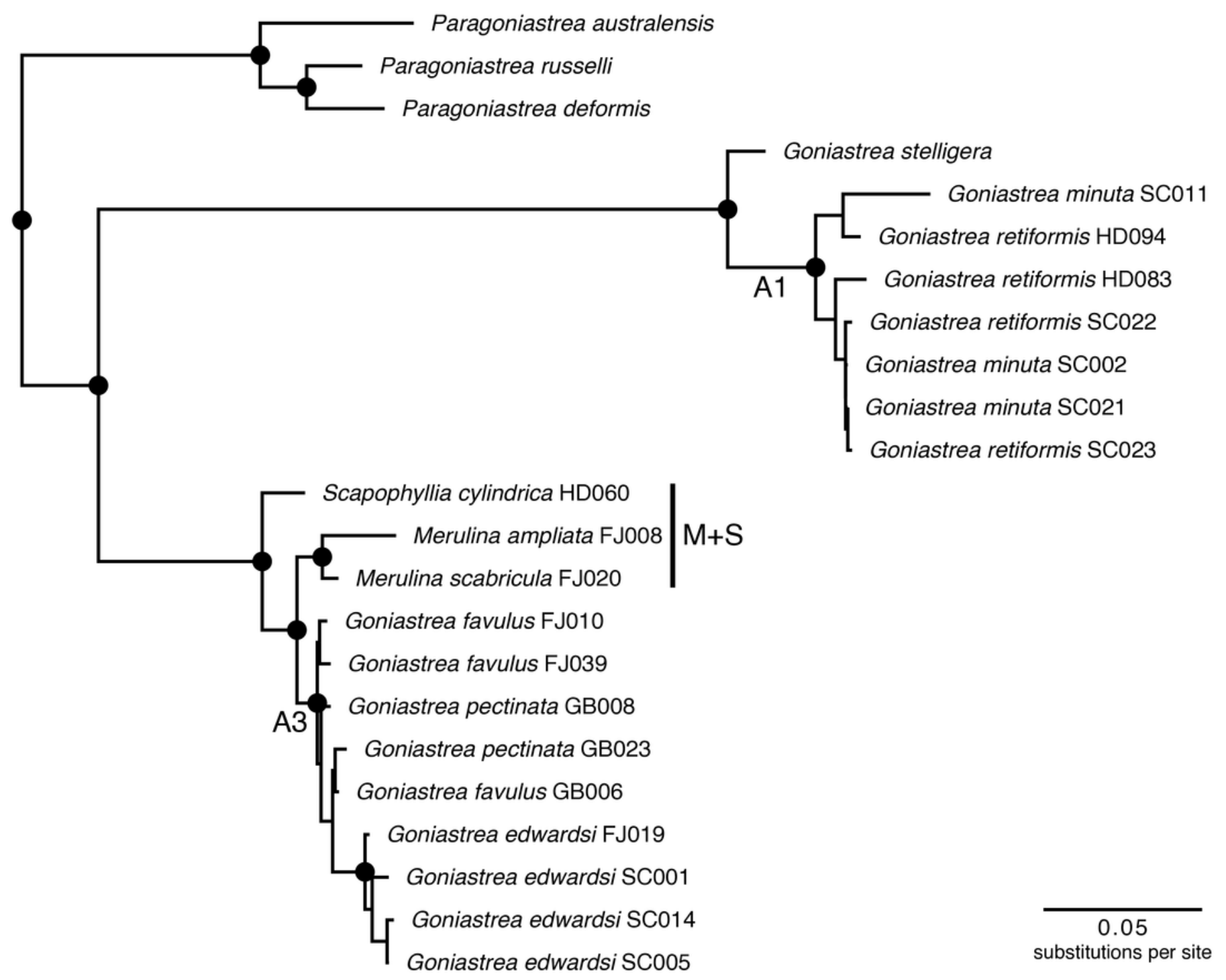


Figure 2

Proportional abundance of sequencing reads recovered.

MiSeq sequencing data for each Symbiodiniaceae genus among coral species examined.

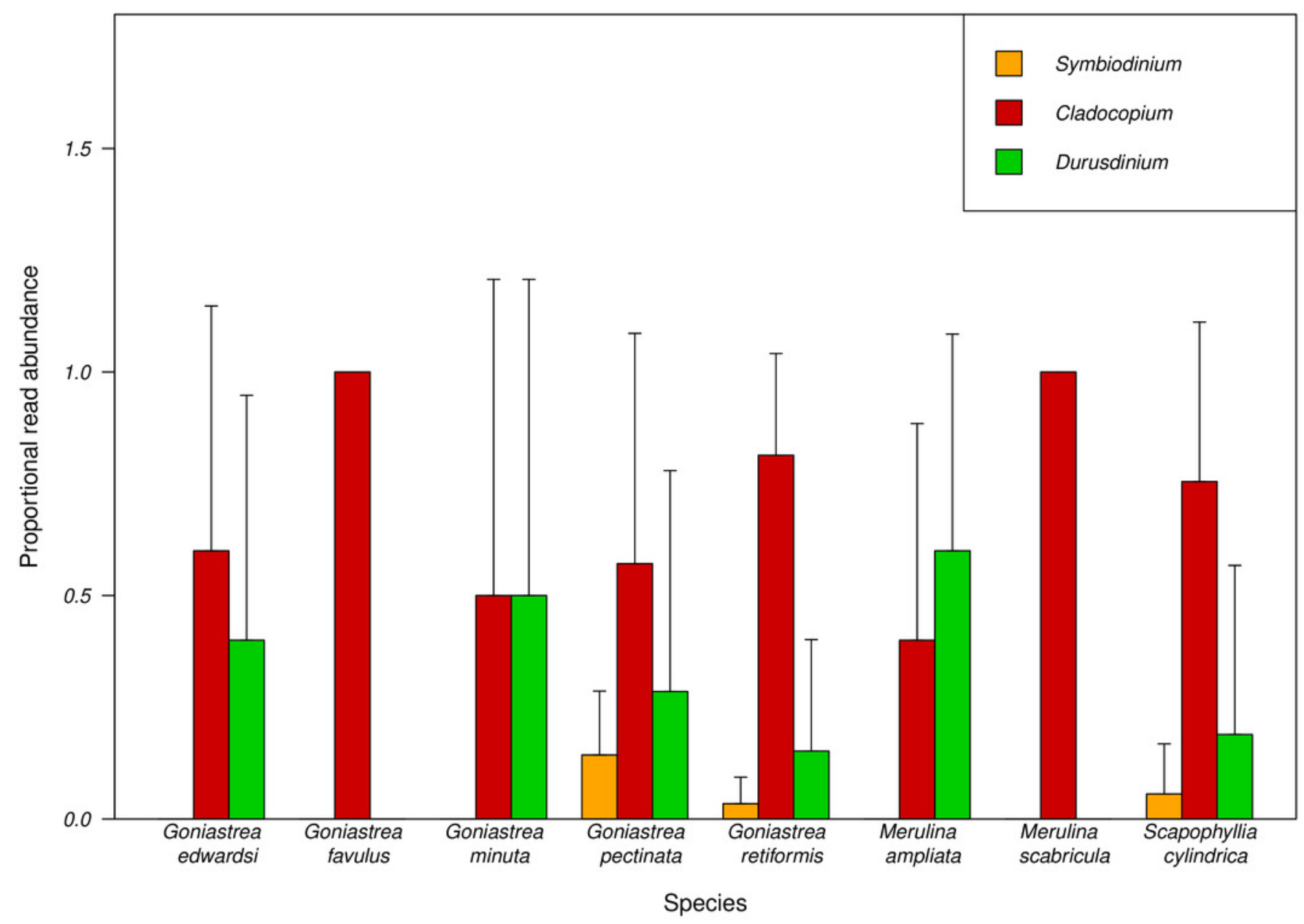


Figure 3

Non-metric multidimensional scaling of Symbiodiniaceae communities.

Analysis of endosymbiont communities in Merulinidae corals based on the Bray-Curtis dissimilarity (top; stress $=0.097$ ) and Jaccard distance (bottom; stress $=0.093$ ) measures of symbiont types with $\geq 10$ reads in each colony. Symbols are distinguished according to host species and locality.
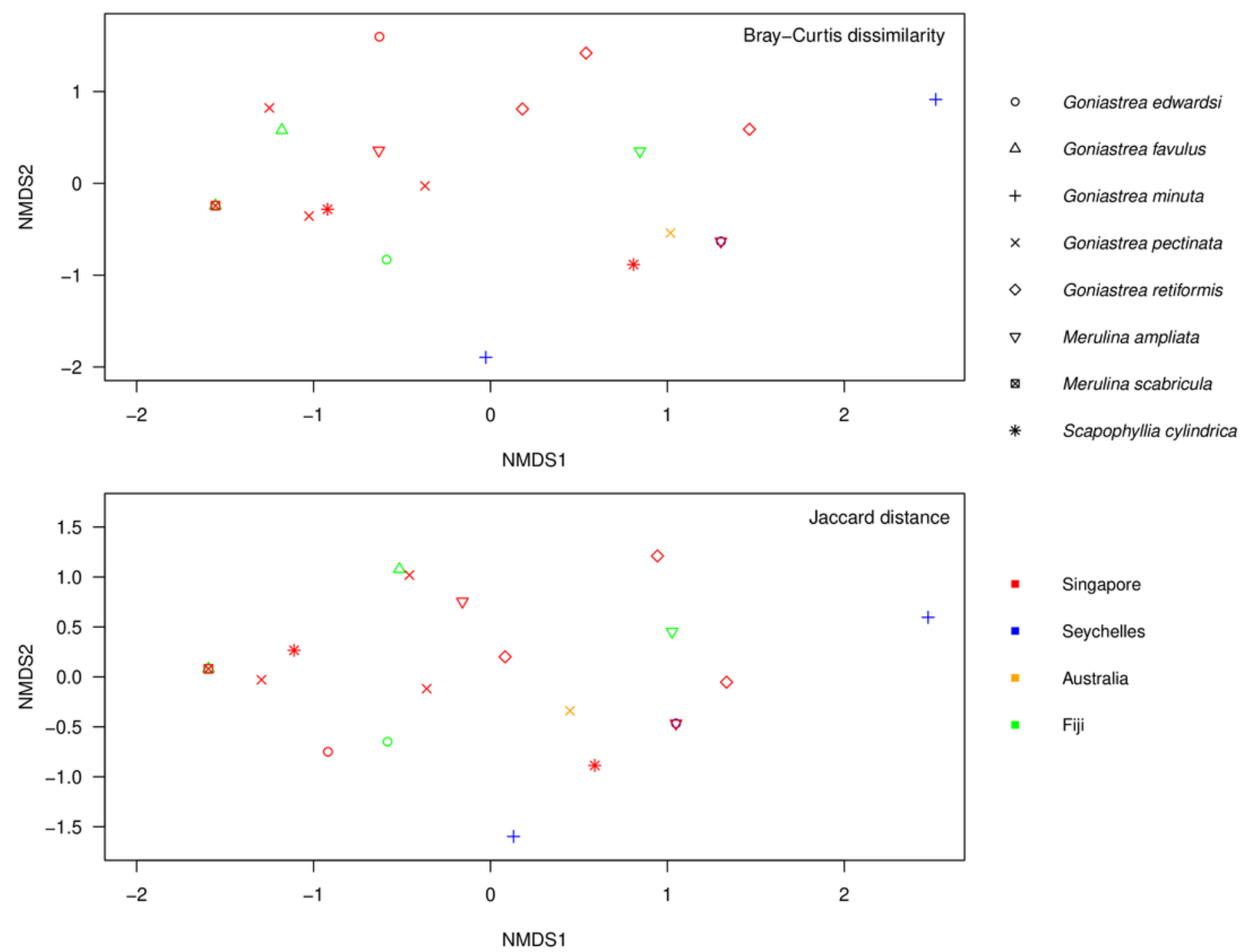

- Singapore

- Seychelles

- Australia

$=\mathrm{Fiji}$ 